\title{
Perovskite Self-Passivation with PCBM for Small Open-Circuit Voltage Loss
}

\author{
Xinglin Zhu', Xinyu Zhao', Lei Li', Yi Peng1, Wenwang Wei', Xuan Zhang1, Mengwei Su1, \\ Yukun Wang ${ }^{1 *}$, Ziqian Chen ${ }^{*}$, Wenhong Sun ${ }^{1,2 *}$ \\ ${ }^{1}$ Research Center for Optoelectronic Materials and Devices, School of Physical Science Technology, Guangxi University, Nanning, \\ China \\ ${ }^{2}$ Guangxi Key Laboratory of Processing for Non-Ferrous Metal and Featured Materials, Guangxi University, Nanning, China \\ Email: ^ykwang0929@163.com, ^czq8676@hotmail.com, ^20180001@gxu.edu.cn
}

How to cite this paper: Zhu, X.L., Zhao, X.Y., Li, L., Peng, Y., Wei, W.W., Zhang, X., Su, M.W., Wang, Y.K., Chen, Z.Q. and Sun, W.H. (2020) Perovskite Self-Passivation with PCBM for Small Open-Circuit Voltage Loss. Energy and Power Engineering, 12, 257-272. https://doi.org/10.4236/epe.2020.126016

Received: May 8, 2020

Accepted: June 9, 2020

Published: June 12, 2020

Copyright $(\odot 2020$ by author(s) and Scientific Research Publishing Inc. This work is licensed under the Creative Commons Attribution International License (CC BY 4.0).

http://creativecommons.org/licenses/by/4.0/

\begin{abstract}
It is well known that $[6,6]$-phenyl- $\mathrm{C}_{61}$-butyric acid methyl ester (PCBM) is a common n-type passivation material in PSCs, usually used as an interface modification layer. However, PCBM is extremely expensive and is not suitable for future industrialization. Herein, the various concentrations of PCBM as an additive are adopted for PSCs. It not only avoids the routine process of spin coating the multi-layer films, but also reduces the PCBM material and cost. Meanwhile, PCBM can passivate the grain surface and modulate morphology of perovskite films. Furthermore, the most important optical parameters of solar cells, the current density $\left(J_{s c}\right)$, fill factor $(\mathrm{FF})$, open-circuit voltage $\left(V_{o c}\right)$ and power conversion efficiencies (PCE) were improved. Especially, when the $\mathrm{PCBM}$ doping ratio in $\mathrm{CH}_{3} \mathrm{NH}_{3} \mathrm{PbI}_{3}\left(\mathrm{MAPbI}_{3}\right)$ precursor solution was $1 \mathrm{wt} \%$, the device obtained the smallest $V_{o c}$ decay (less than 1\%) in the p-i-n type PSCs with poly (3,4-ethylenedioxythiophene):poly (styrene sulfonate) (PEDOT:PSS) as hole transport layer (HTL) and fullerene $\left(\mathrm{C}_{60}\right)$ as electron transport layer (ETL). The PSCs $V_{o c}$ stability improvement is attributed to enhanced crystallinity of photoactive layer and decreased non-radiative recombination by PCBM doping in the perovskites.
\end{abstract}

\section{Keywords}

Self-Passivation, Small Open-Circuit Voltage Loss, PCBM

\section{Introduction}

Organic-inorganic hybrid PSCs have recently drawn tremendous attention because of their simple solution processing, tunable optoelectronic properties, high carrier migration, low photo exciton binding energy, excellent bi-polar carrier 
transport capacity, efficient conduction of electrons and holes, rapid increase in power conversion efficiencies (PCE) [1]-[8]. In 2009, Miyasaka and coworkers introduced a seminal work involving organic perovskite solar cells demonstrated with a low PCE of 3.8\% [9]. After a decade of development, the highest recorded and certified PCE has been reached $25.2 \%$, meeting the needs of commercial solar cells [10]. However, photovoltaic cells are more expensive than conventional energy sources, such as fossil fuels, wind, hydro, and nuclear, due to the manufacturing materials involved. Reducing the amount of materials used or synthesizing cheaper alternatives with similar functions to facilitate the commercialization of photovoltaic cells was necessary [11]. The PSCs device structure can be divided into two categories, a normal $n-i-p$ architecture and an inverted $p-i-n$ architecture [12] [13] [14] [15]. The normal n-i-p structure often needs mesoporous $\mathrm{TiO}_{2}$ as the ETL, and the production of this material requires high temperature environment $\left(>400^{\circ} \mathrm{C}\right)$ [16] [17]. For PSCs with an inverted p-i-n structure, the conventional organic p-type material is usually PEDOT:PSS [14] [18], poly (triarylamine) (PTAA) [19] [20]. In contrast, inorganic p-type materials have nickel (II) oxide $\left(\mathrm{NiO}_{x}\right)$ [21] [22], copper thiocyanate (CuSCN) [23] [24], and copper iodide ( $\mathrm{CuI}$ ) [24] [25], while the n-type material is mainly fullerenes and its derivatives. Therefore, researchers prefer inverted $\mathrm{p}-\mathrm{i}-\mathrm{n}$ structures involving a low temperature preparation process and low hysteresis effect [26].

In the production of PSCs, the commonly used electronic transport materials and electronic trap states passivator of $\mathrm{p}-\mathrm{i}-\mathrm{n}$ structure include PCBM, $\mathrm{C}_{60}$ and other fullerene derivatives [27] [28] [29]. Many studies have proved that in high-efficiency PSCs, $\mathrm{C}_{60}$ and its derivative PCBM have excellent electron acceptability due to the spherical structural strain, hence making this kind of material the most effective passivation agent. However, since the PCBM has a higher electronic acceptance and excellent passivation effect on the active layer, it is widely used as a material of ETL. However, as an ETL passivation layer, $\mathrm{C}_{60}$ is capable of passivation depth defects, but its passivation effect is worse than that of PCBM. Due to its much cheaper price, the use of $\mathrm{C}_{60}$ as a passivation layer device promotes the commercialization process. In this work, considering the high price of PCBM, the method of micro-doping not only avoids the tedious process of spin coating multi-layer film, but also produces high-quality perovskite-PCBM heterojunction photoactive film [29]. In the whole device, the quality of active layer is the most critical factor affecting the PCE of photovoltaic cells. To obtain dense perovskite film, the purity of precursor solution should be high, and the solute should be completely dissolved. The solubility of lead iodide $\left(\mathrm{PbI}_{2}\right), \mathrm{Me}-$ thyl ammonium iodide (MAI), and PCBM in organic solvents is limited, especially after the incorporation of PCBM. Therefore, in the preparation of doping solution, PCBM is stirred first and dissolved with N,N-Dimethyl formamide (DMF) and Dimethyl sulfoxide (DMSO) mixed solvent, and then perovskite precursors are added to form a slightly doped perovskite precursor solution. The addition of PCBM affected the morphology of perovskite, and an appropriate amount of PCBM can increase the grain size of perovskite film. A simple and 
convenient one-step method is used to spin coat the perovskite films. Figure 1(a) shows the structure of the devices in this work. Although the PSCs have higher carrier mobility and longer carrier life-times, the whole device will still have non-radiative recombination, which limits their $V_{o c}$ value below the Shockley-Queisser theory [30] [31]. In this experiment, it was found that doped PCBM could not only passivate perovskite, increase grain size, but also improve the cells' $V_{o c}$. When the $\mathrm{PCBM}$ doping concentration in $\mathrm{MAPbI}_{3}$ precursor solution was from $0-1 \mathrm{wt} \%$, the $J_{s c} \mathrm{FF}$ and $V_{o c}$ of the devices increased, the $V_{o c}$ of the planar ITO/PEDOT:PSS/MAPbI ${ }_{3}$ with $\mathrm{PCBM} / \mathrm{C}_{60} / \mathrm{BCP} / \mathrm{Ag}$ (p-i-n) device structure reached more than $0.99 \mathrm{~V}$, and the $V_{o c}$ loss was less than $1 \%$ compared with the theoretical value.

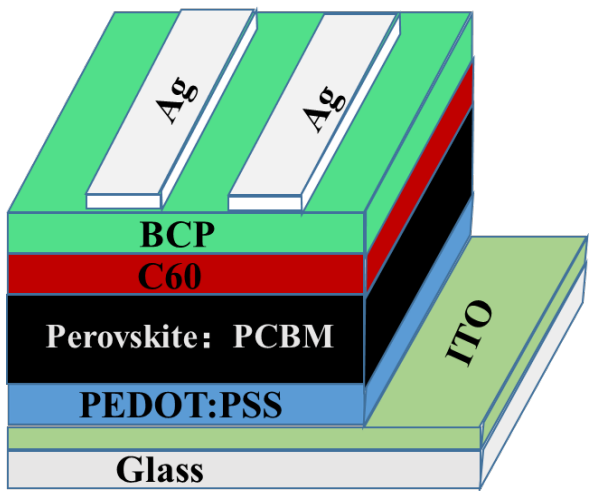

(a)

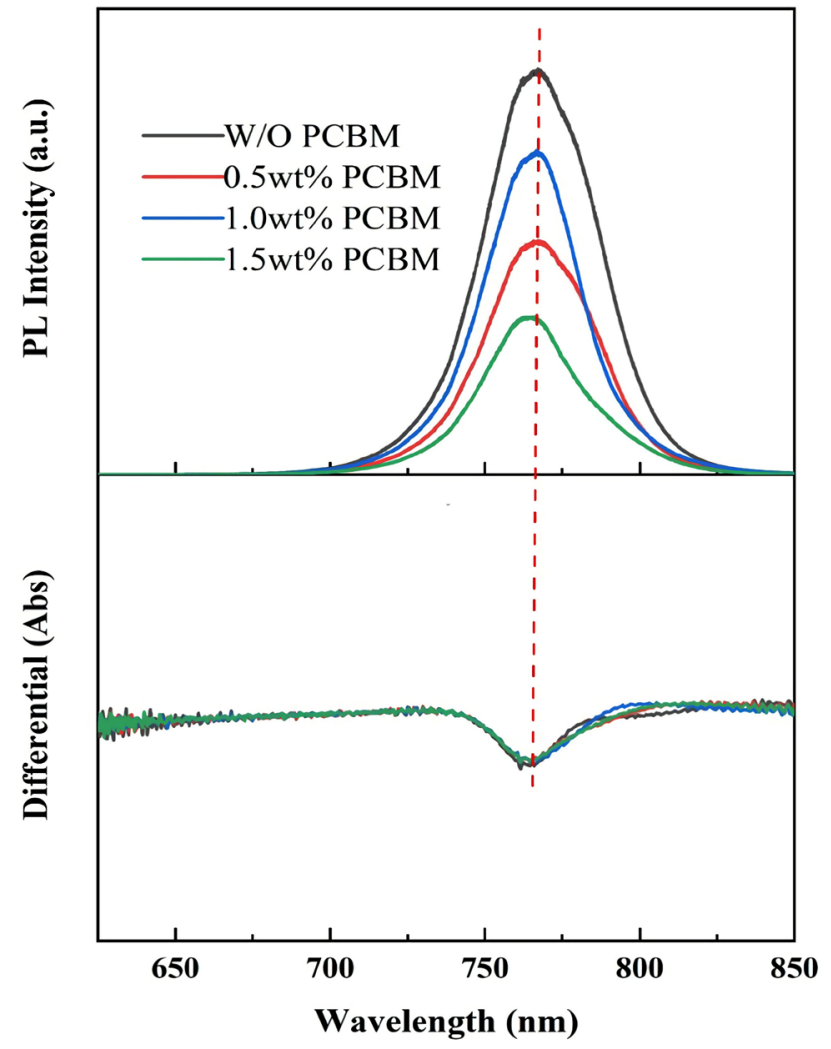

(b) 


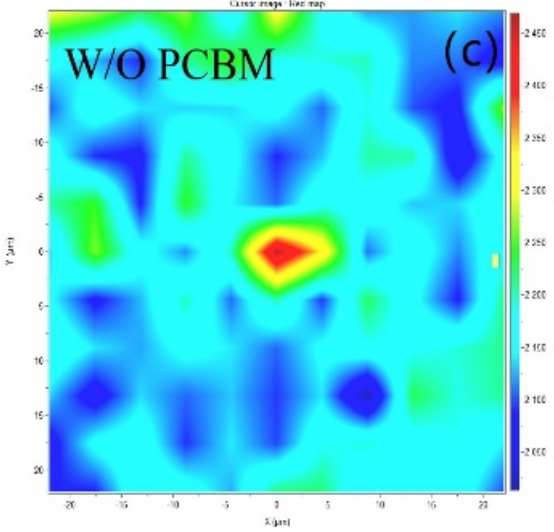

(c)

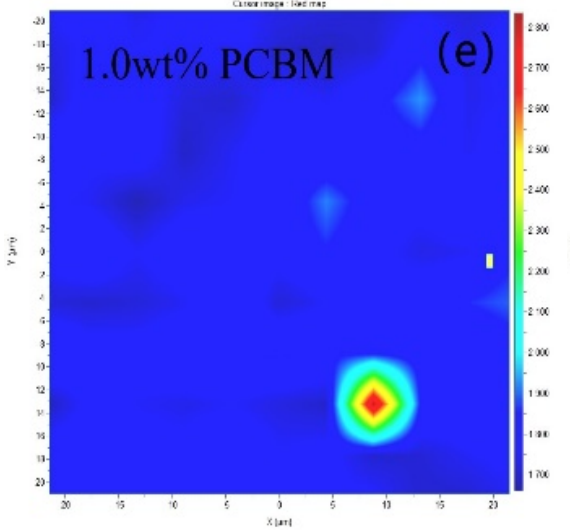

(e)

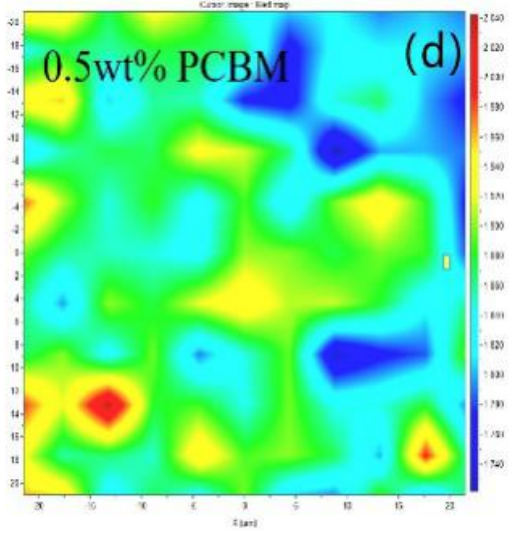

(d)

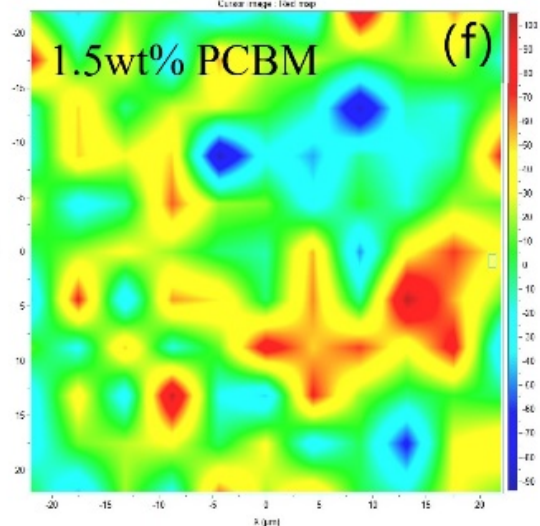

(f)

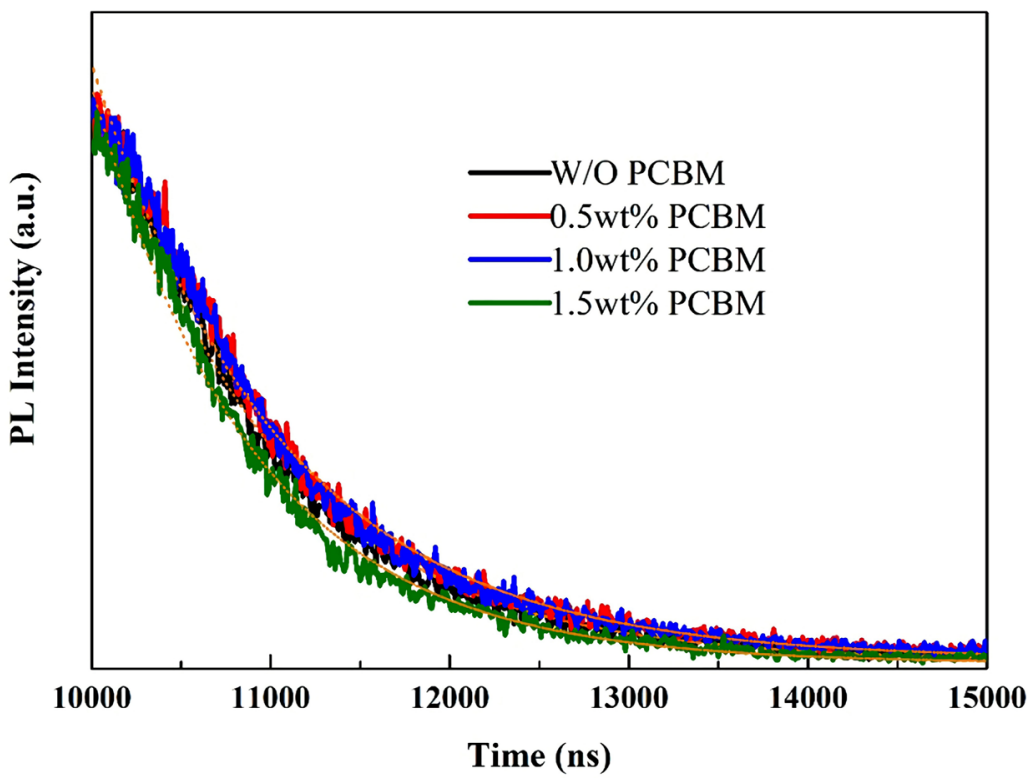

(g)

Figure 1. (a) Device structure of planar heterojunction perovskite solar cells; (b) Steady state PL spectrum of perovskite films deposited on the ITO/PEDOT:PSS and the differential of the absorption spectrum curve. Both of the PL intensity and the absorption did not change the emission peak centered; (c)-(f) PL mapping; (g) PL decay curves of perovskite doped with various concentrations of PCBM. 


\section{Experimental Section}

\subsection{Materials}

Lead iodide $\left(\mathrm{PbI}_{2}, 99.8 \%\right)$ and bathocuproine (BCP, 99\%) were purchased from the Xi'an Polymer Light Technology Corp, $\mathrm{CH}_{3} \mathrm{NH}_{3} \mathrm{I}$ (MAI) was purchased from Greatcell solar Australia Pty Ltd, PCBM (99.5\%) was purchased Nano-C, PEDOT:PSS conductive liquid was purchased from Heraeus, $\mathrm{C}_{60}$ (99.9\%) was purchased from Liaoning Youxuan New Energy Technology Co., Ltd. We obtained the Silver (Ag, $\geq 99.9 \%)$ and the solvents, which include DMF ( $\geq 99 \%)$ and DMSO ( $\geq 99.9 \%$ ) from Sigma-Aldrich. All chemicals were used as received without further purification.

\subsection{Device Fabrication}

The patterned ITO glass substrates were subsequently cleaned in an ultrasonicator with ITO detergent, acetone, isopropyl alcohol and deionized (DI) water for 15 minutes each. After that, the ITO substrates were treated in a UV ozone oven for $15 \mathrm{~min}$. First, PEDOT:PSS was spin-coated at $4000 \mathrm{rpm}$ for $30 \mathrm{~s}$ onto the ITO glass substrate, followed by annealing at $150^{\circ} \mathrm{C}$ for $10 \mathrm{~min}$. Pristine perovskite precursor solution was prepared by dissolving $\mathrm{PbI}_{2}$ and MAI (1:1 molar ratio) in the solvent mixture of DMF and DMSO (9:1 v/v) for a total concentration of 1.5 $\mathrm{m}$ in the glovebox. For doped perovskite precursor solution, perovskite concentration remained unchanged, and PCBM concentration was calculated according to the amount of $\mathrm{PbI}_{2}$. The solution was stirred at room temperature overnight. Then, the perovskite layer was spun onto the hole transport layer (HTL) at 3000 rpm for $10 \mathrm{~s}$ and $5000 \mathrm{rpm}$ for $50 \mathrm{~s}$. Next the substrate was annealed on a hot plate at $100^{\circ} \mathrm{C}$ for $20 \mathrm{~min}$. Finally, the devices were finished by thermally evaporating $\mathrm{C}_{60}(50 \mathrm{~nm}), \mathrm{BCP}(8 \mathrm{~nm})$, and $\mathrm{Ag}(80 \mathrm{~nm})$ in the order.

\subsection{Optoelectronic Characterization}

The perovskite thin film surface morphology images were characterized by atomic force microscopy (Hitachi AFM 5100N). The top-view scanning electron microscopy (SEM, JEOL JEM5610) of the perovskite, which were spin coated on ITO/PEDOT:PSS substrates. Steady state photoluminescence (PL) spectra and PL mapping were acquired by Raman spectrometer (LabRAM HR Evolution) with $532 \mathrm{~nm}$ laser unit, which was manufactured by HORIBA FRANCE SAS. The time-resolved photoluminescence spectra (FLS1000, TRPL) were obtained with the range of wavelength from $600 \mathrm{~nm}$ to $800 \mathrm{~nm}$ by exciting at $532 \mathrm{~nm}$ laser. The absorption spectra of the perovskite films were determined by UV-visible spectrophotometer. The crystallinity of the perovskite thin film was monitored by X-ray diffraction (XRD, Rigaku, SmartLab3kW). The current density-voltage $(J-V)$ curves were measured using a solar simulator with a source meter (Keithley 2400) at $100 \mathrm{~mW} / \mathrm{cm}^{2}$, AM $1.5 \mathrm{G}$ illumination. The $J-V$ curves were measured by scanning from negative bias $(-0.2 \mathrm{~V})$ to forward bias $(+1.2$ $\mathrm{V})$. The External quantum efficiency (EQE) spectra were measured with an EQE 
measurement system, and the light intensity at each wavelength was calibrated with a standard single-crystal Si photovoltaic cell. All optical and electrical measurements were performed at room temperature.

\section{Results and Discussion}

PL spectra are an effective and non-destructive method to characterize the optical properties of semiconductor materials. By analyzing a PL spectrum, the bandgap, impurity type and activation energy of semiconductor material can be obtained. The TRPL indicates that electron relaxation and non-radiative recombination physical mechanisms can be obtained by detecting the change of photoluminescence intensity at a certain wavelength with time by pulsed excitation. PL and TRPL were used to investigate the effect of the PCBM additive on recombination and carrier lifetime of the perovskite film. It can be seen from the pristine and PCBM-perovskite thin films PL spectrum shown in Figure 1(b) that the PL emission peak centered at $766 \mathrm{~nm}$ did not change even when the dose of PCBM in perovskite films increased, and the obtained band gap of perovskite was about $1.61 \mathrm{eV}$. However, the PL intensity increased with different concentrations of PCBM. When the concentration of PCBM was $1.0 \mathrm{wt} \%$, the PL intensity was the highest, but when the additive concentration was more than 1.0 wt\%, the PL strength was weak, indicating that the crystallinity of the photoactive layer was the best when the additive concentration was $1.0 \mathrm{wt} \%$. Meanwhile, in order to analyze the uniformity of perovskite films, Figures 1 (c)-(f) showed the PL mapping of the micro-region $(20 \mu \mathrm{m} \times 20 \mu \mathrm{m})$ centered on the emission peak of $766 \mathrm{~nm}$, showing the composition uniformity of perovskite thin films doped with PCBM of different concentrations. Furthermore, the TRPL spectrum was used to evaluate the carrier extraction from the devices. The spectra were fitted by biexponential decay function of $y=y_{0}+A_{1} * \mathrm{e}^{-x / \tau_{1}}+A_{2} * \mathrm{e}^{-x / \tau_{2}}$, and the fast decay constant $\tau_{1}$ was correlated to surface property, while the slow decay constant $\tau_{2}$ was associated with bulk property [32]. Herein, we calculated the average decay lifetime according to the equation of $\tau_{\text {avg }}=\sum A_{i} \tau_{i}^{2} / \sum A_{i} \tau_{i}$. The obtained results suggest the existence of two quenching processes including the carrier extraction occurred at the interfaces of PEDOT:PSS/perovskite with different PCBM as well as the carrier trap recombination. As shown in Figure 1(g), the average carrier lifetime of ITO/PEDOT:PSS/perovskite films with different PCBM concentrations (W/O, $0.5 \mathrm{wt} \%, 1.0 \mathrm{wt} \%$ and $1.5 \mathrm{wt} \%)$ were $982 \mathrm{~ns}, 1057$ ns, 1056 ns, and 904 ns, respectively. These results indicated a faster photogenerated carrier extraction for ITO/PEDOT:PSS/perovskite films with slight PCBM, which was beneficial to the $J_{s c}$ and PCE values of the devices. However, when the additive of PCBM concentration continues to increase, the photogenic carrier life would decrease sharply.

The UV-vis absorption spectra of the investigated perovskite films are shown in Figure 2(a). It can be seen from the UV-vis spectra that the $\mathrm{MAPbI}_{3}$ perovskite doped with the PCBM exhibited a higher optical absorption than the pristine 


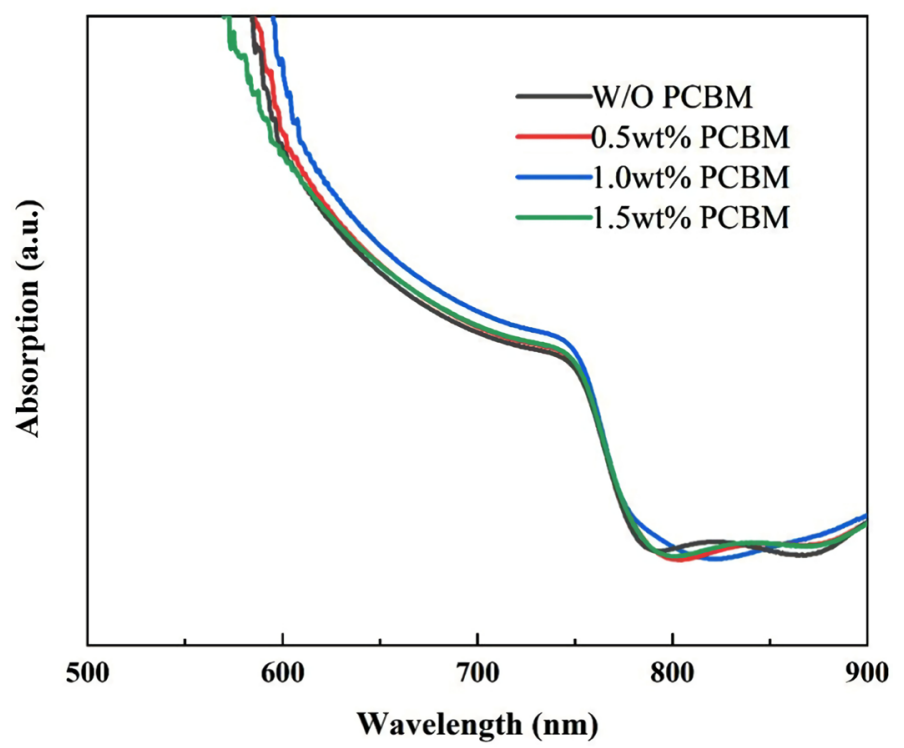

(a)

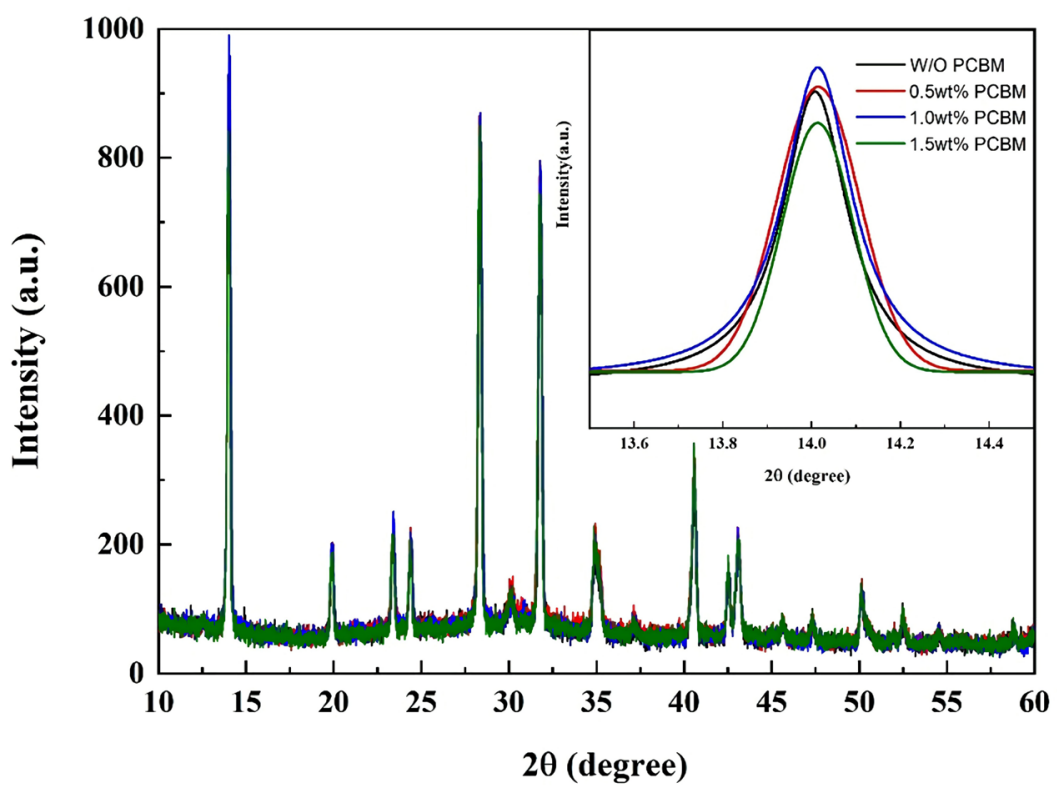

(b)

Figure 2. (a) UV-Vis absorption spectrum of the perovskite films with different doses of PCBM; (b) XRD patterns of pristine perovskite and PCBM-perovskite films.

photoactive layer across the entire visible spectrum. Generally, UV-vis absorption is mainly caused by the transition of electrons from the ground state to the excited state. Meanwhile, in semiconductor materials, the transition of electrons from the ground state to the excited state is related to their energy band structure. Therefore, the absorption law of light must be related to their energy band structure. The differential of the absorption spectrum curve and PL spectrum were shown in Figure 1(b), and it was found that the emission peak position of PL was consistent with the cutoff point of the absorption spectrum. This confirms the bandgap size of perovskite film. 

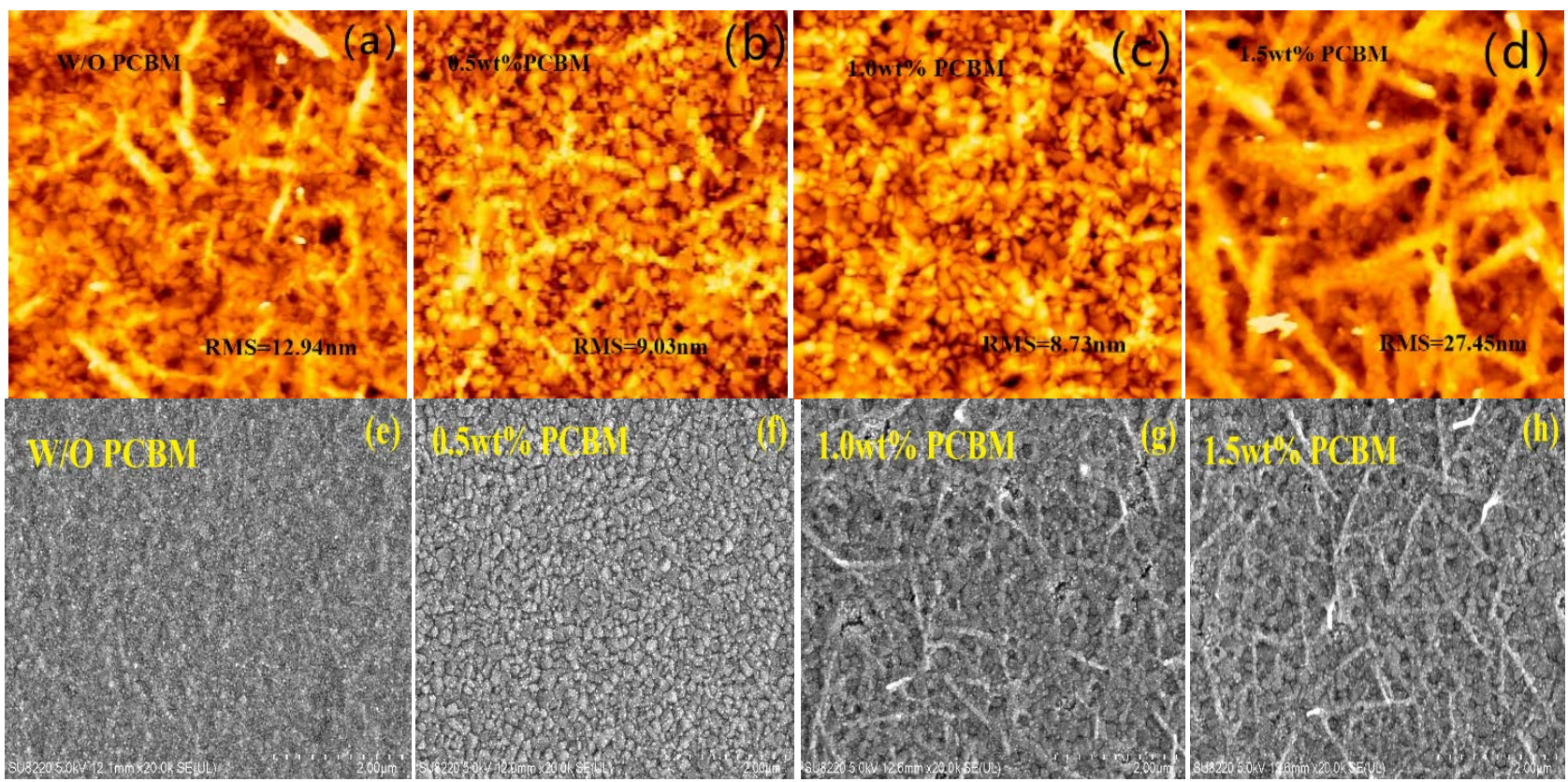

Figure 3. AFM images of $\mathrm{MAPbI}_{3}$ perovskite thin films with different fabrication approaches. (a) W/O PCBM; (b) 0.5 wt\% PCBM; (c) $1.0 \mathrm{wt} \%$ PCBM; (d) $1.5 \mathrm{wt} \%$ PCBM; (e)-(h) Top-view SEM morphology characterization of perovskite MAPbI $_{3}$ films without and with PCBM $0.5 \mathrm{wt} \%, 1.0 \mathrm{wt} \%$, and $1.5 \mathrm{wt} \%$. 
$27.4 \mathrm{~nm}$. This can be confirmed by the SEM morphology of the involved perovskite film. The amount of additive PCBM amount in perovskite films played an important role in changing the surface of perovskite films and devices. It can be seen from Figures 3(e)-(h) that the grain size would increase with the addition of PCBM. When the doping concentration of PCBM was $1 \mathrm{wt} \%$, macromolecular agglomeration began to appear. As the additive doping concentration continues to increase, the agglomeration of PCBM became increasingly evident, and the surface morphology decreased.

It was found from a series of doping concentration $J$ - $V$ curves (Figure 4(a)) that the concentration of PCBM in the perovskite precursor would affect the photovoltaic parameters of the whole device. The corresponding photovoltaic parameters are listed in Table S1 (Support information). The $J_{s c}$ of the device is related to the band gap, thickness, surface morphology, and carrier transport properties of the perovskite layer [33]. The addition of a certain concentration of PCBM can improve carrier mobility and thus obtain a higher $J_{s c}$ as illustrated in Figure 4(b). It was found that the FF of the device increased when the additive was very small (Figure $4(\mathrm{c})$ ). Since the FF of the device is affected by series and parallel resistance, it reflects the ideal degree of the diode of the device. Especially for the $V_{o c}$ of the device, When PCBM was added to the photoactive film as an additive, the $V_{o c}$ of the device changed from 0.82 to $0.99 \mathrm{~V}$ (Figure $4(\mathrm{~d})$ ). Generally, the inverted p-i-n PSCs with PEDOT:PSS as HTL and $\mathrm{C}_{60}$ as ETL exhibit a $V_{o c}$ less than $1.0 \mathrm{~V}$. Theoretically, the $V_{o c}$ of the PSCs are determined by the highest occupied molecular orbital (HOMO, $-5.5 \mathrm{eV}$ ) level of the donor and the lowest unoccupied molecular orbital (LUMO, $-4.5 \mathrm{eV}$ ) level of the acceptor [34] [35] [36] [37], so the $V_{o c}\left(V_{o c} \approx 1 / e\left(\left|E_{H O M O}^{\text {donor }}\right|-\left|E_{L U M O}^{\text {acceptor }}\right|\right)\right)$, where $E_{H O M O}^{\text {donor }}$ is the HOMO level of the donor and $E_{L U M O}^{\text {acceptor }}$ is the LUMO level of the acceptor [38] [39]. Combining with the above equation, it can be seen from the energy level diagram (Figure $4(\mathrm{e})$ ) that when the concentration of photoactive layer doped PCBM was $1 \mathrm{wt} \%$, the $V_{o c}$ loss of the device was $1 \%$. In theory, for PSCs, the $V_{o c}$ loss is related to the perovskite bandgap $\left(E_{g}\right)$ and the elementary charge $(e)$, determined by the equation of ( $\left.V_{\text {loss }}=E_{g} / e-V_{o c}\right)$ [40] [41] [42]. In general, the high $V_{o c}$ loss can be attributed to the high trap density of the perovskite surface causing severe interface defects non-radiative recombination, and an undesired energy-level mismatching between the n-type layer and p-type in the device [40] [43]. The loss mechanism of $V_{o c}$ is an important and necessary research topic for ultra-efficient PSCs. According to recent literatures, the research on high-efficiency PSCs and low-loss $V_{o c}$ and the development of high efficient crystalline silicon solar cells show that it is very necessary to improve the $V_{o c}$ of solar cells. In recent years, PSCs have made continuous breakthroughs in efficiency. The most important means is to improve carrier management by using interface passivation technology to reduce interface non-radiation recombination and increase $V_{o c}$ to improve efficiency. In the solar cell measuring process, PCE (the efficiency of converting solar light energy into electrical energy) is the most important. This directly reflects the performance of the devices. The PCE 


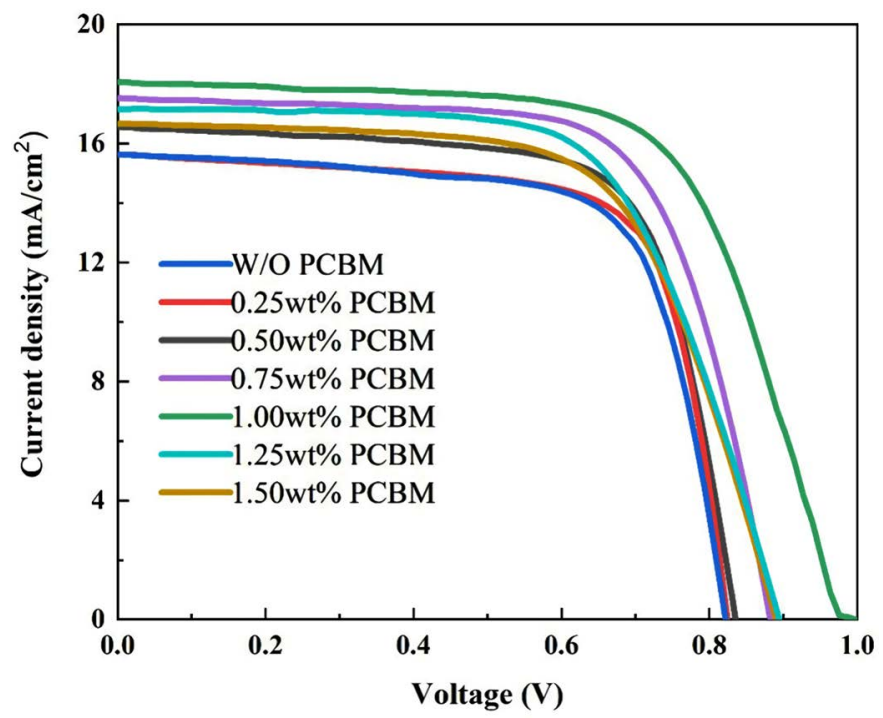

(a)

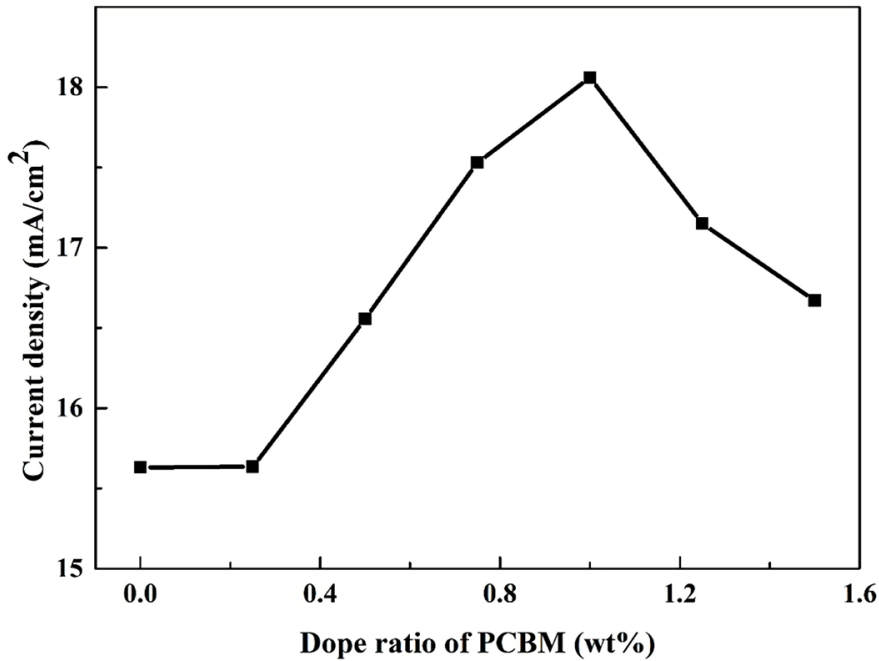

(b)

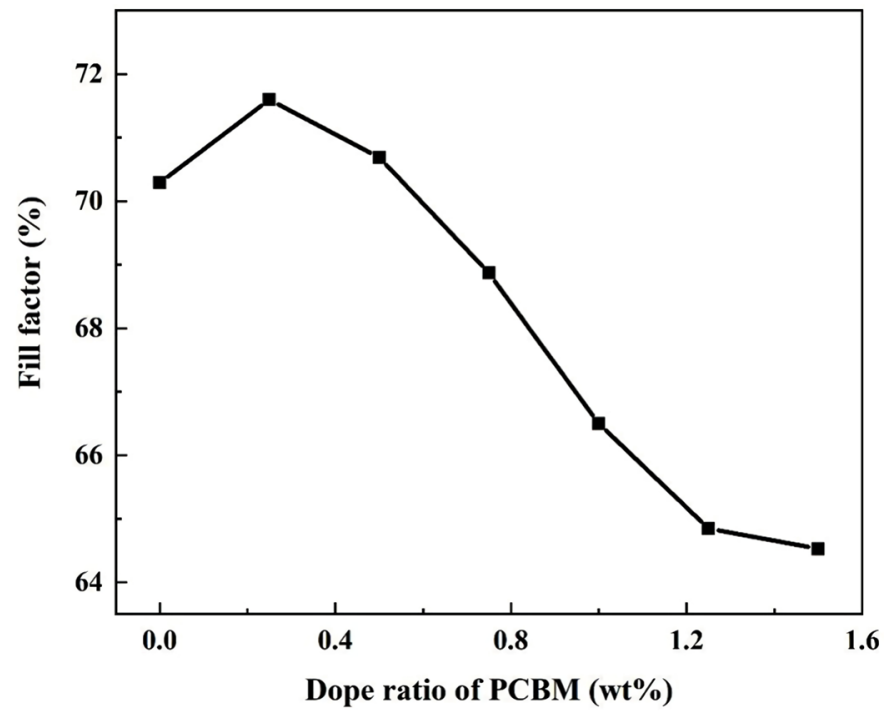

(c) 


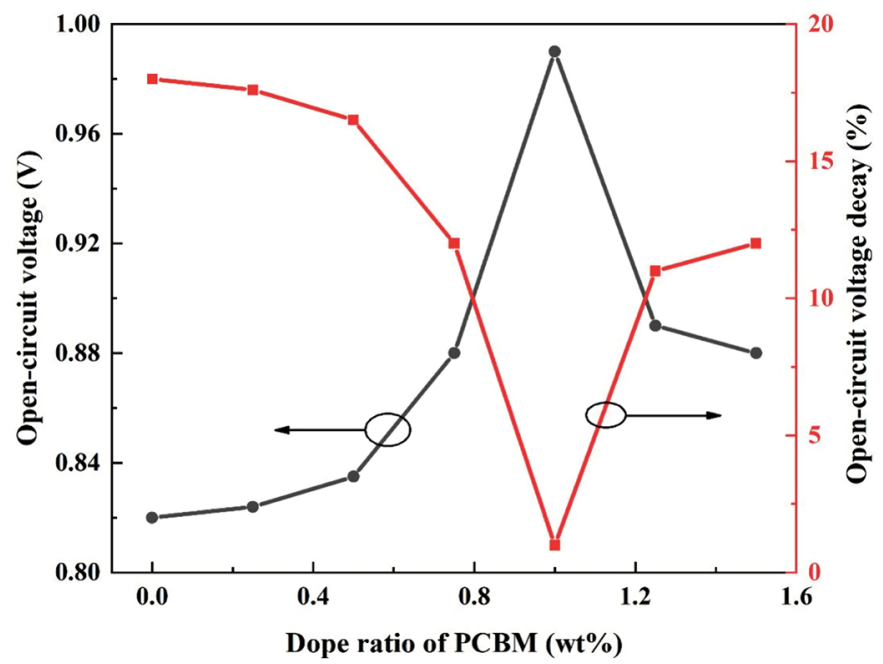

(d)

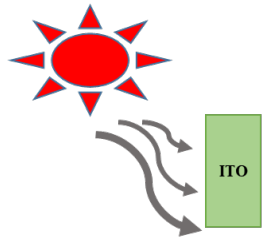

$-4.7 \mathrm{eV}$

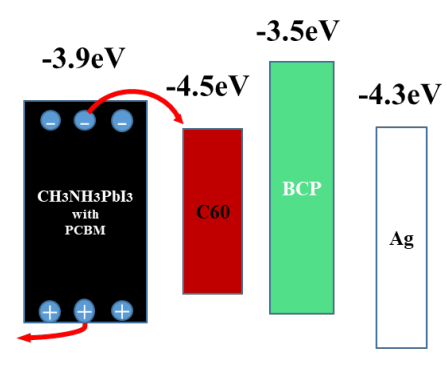

$-5.5 \mathrm{eV}$

(e)

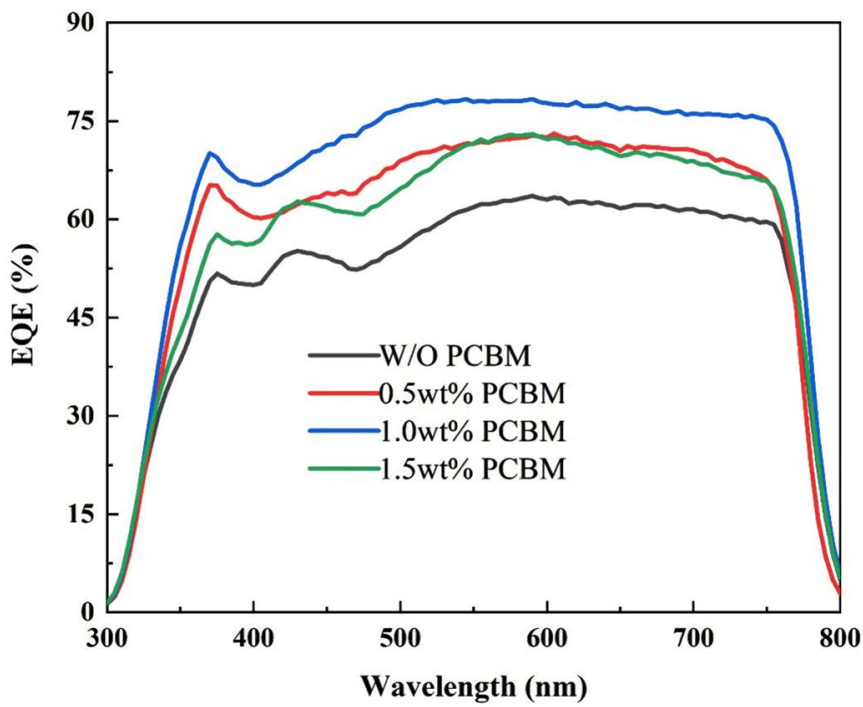

(f)

Figure 4 (a) The typical $J$ - $V$ curve of the device with different dope ratio of PCBM and without PCBM as additive under one-sun $\left(100 \mathrm{~mW} / \mathrm{cm}^{2}\right)$ conditions; (b) The current density of the devices with various dope ratio of PCBM; (c) The fill factor of the devices with various dope ratio of PCBM; (d) The open-circuit voltage and the voltage loss of the devices with various dope ratio of PCBM; (e) Schematic illustration of energy level of the devices; (f) EQE spectra for pristine and PCBM as additive in the absorber layer perovskite solar cells. 
value of the cells at different of PCBM ratio is shown in Figure S1 (Support information). It can be seen from Figure 4(f) that a noticeable EQE enhancement was characterized for PCBM incorporated PSCs. Furthermore, the EQE spectrum was also measured for devices constructed from different additive concentrations of PCBM in order to evaluate the efficient photocurrent at various wavelengths and to provide an additional measure of material band gap from the beginning to the end of photocurrent generation.

\section{Conclusion}

In summary, through a series of optical characterization such as PL, SEM and UV-vis, it was shown that the addition of small amount of PCBM to the precursor can form a self-passivating, high-quality perovskite thin film. As a result, the solar cells obtain a higher $V_{o c} J_{s c}$ and FF. From the theoretical formula, the attained of $0.99 \mathrm{~V}$ is among the smallest $V_{o c}$ loss for $\mathrm{p}-\mathrm{i}-\mathrm{n}$ type PSCs with PEDOT:PSS as HTL and $\mathrm{C}_{60}$ as ETL in the obtained perovskite band gap of 1.61 $\mathrm{eV}$. Systematic perovskite thin film optical characterization of the PSCs $V_{o c}$ enhancement indicated that the improvement is mainly attributed to the enhanced crystallinity of photoactive layer and interface efficient charge carrier dissociation with decreased non-radiative recombination. Therefore, PCBM as micro-additive may be applicable to other organic-inorganic hybrid photoelectronic devices.

\section{Acknowledgements}

This work was supported financially by the fund for Bagui Talent of Guangxi Province (No. T3120097921), Talent Model Base (No. AE31200065) and Guangxi University Foundation (No. A3120051010), China.

\section{Conflicts of Interest}

There are no conflicts to declare.

\section{References}

[1] Dong, Q.F., Fang, Y.J., Shao, Y.C., Mulligan, P., Qiu, J., Cao, L. and Huang, J.S. (2015) Electron-Hole Diffusion Lengths $>175 \mu \mathrm{m}$ in Solution-Grown $\mathrm{CH}_{3} \mathrm{NH}_{3} \mathrm{PbI}_{3}$ Single Crystals. Science, 347, 967-970. https://doi.org/10.1126/science.aaa5760

[2] Zhao, Y. and Zhu, K. (2016) Organic-Inorganic Hybrid Lead Halide Perovskites for Optoelectronic and Electronic Applications. Chemical Society Review, 45, 655-689. https://doi.org/10.1039/C4CS00458B

[3] Yang, W.S., Park, B.W., Jung, E.H., Jeon, N.J., Kim, Y.C., Lee, D.U., Shin, S.S., Seo, J., Kim, E.K., Noh, J.H. and Seok, S.I. (2017) Iodide Management in Formamidinium-Lead-Halide-Based Perovskite Layers for Efficient Solar Cells. Science, 356, 1376-1379. https://doi.org/10.1126/science.aan2301

[4] Wu, W.-Q. and Wang, L.Z. (2019) A 3D Hybrid Nanowire/Microcuboid Optoelectronic Electrode for Maximised Light Harvesting in Perovskite Solar Cells. Journal of Materials Chemistry, 7, 932-939. https://doi.org/10.1039/C8TA09806A

[5] Liu M., Johnston, M.B. and Snaith, H.J.J.N. (2013) Efficient Planar Heterojunction 
Perovskite Solar Cells by Vapour Deposition. Nature, 501, 395-398. https://doi.org/10.1038/nature12509

[6] Shi, D., Adinolfi, V., Comin, R., Yuan, M., Alarousu, E., Buin, A., Chen, Y., Hoogland, S., Rothenberger, A., et al. (2015) Low Trap-State Density and Long Carrier Diffusion in Organolead Trihalide Perovskite Single Crystals. Science, 347, 519-522. https://doi.org/10.1126/science.aaa2725

[7] Im, J.-H., Jang, I.-H., Pellet, N., Grätzel, M. and Park, N.-G. (2014) Growth of $\mathrm{CH}_{3} \mathrm{NH}_{3} \mathrm{PbI}_{3}$ Cuboids with Controlled Size for High-Efficiency Perovskite Solar Cells. Nature Nanotechnology, 9, 927-932. https://doi.org/10.1038/nnano.2014.181

[8] Fan, J., Jia, B. and Gu, M. (2014) Perovskite-Based Low-Cost and High-Efficiency Hybrid Halide Solar Cells. Photonics Research, 2, 111-120. https://doi.org/10.1364/PRJ.2.000111

[9] Kojima, A., Teshima, K., Shirai, Y. and Miyasaka, T. (2009) Organometal Halide Perovskites as Visible-Light Sensitizers for Photovoltaic Cells. Journal of the American Chemical Society, 131, 6050-6051. https://doi.org/10.1021/ja809598r

[10] National Renewable Energy Laboratory (NREL) Best Research-Cell Efficiencies. https://www.nrel.gov/pv/cell-efficiency.html

[11] Chen, Q., Zhou, H., Hong, Z., Luo, S., Duan, H.-S., Wang, H.-H., Liu, Y., Li, G. and Yang, Y. (2013) Planar Heterojunction Perovskite Solar Cells via Vapor-Assisted Solution Process. Journal of the American Chemical Society, 136, 622-625. https://doi.org/10.1021/ja411509g

[12] Meng, L., You, J., Guo, T.-F. and Yang, Y. (2015) Recent Advances in the Inverted Planar Structure of Perovskite Solar Cells. Accounts of Chemical Research, 49, 155-165. https://doi.org/10.1021/acs.accounts.5b00404

[13] Jiang, Q., Zhang, L., Wang, H., Yang, X., Meng, J., Liu, H., Yin, Z., Wu, J., Zhang, X. and You, J. (2016) Enhanced Electron Extraction Using $\mathrm{SnO}_{2}$ for High-Efficiency Planar-Structure $\mathrm{HC}\left(\mathrm{NH}_{2}\right)_{2} \mathrm{PbI}_{3}$-Based Perovskite Solar Cells. Nature Energy 2, Article No. 16177. https://doi.org/10.1038/nenergy.2016.177

[14] Seo, J., Park, S., Kim, Y.C., Jeon, N.J., Noh, J.H., Yoon, S.C. and Seok, S.I. (2014) Benefits of Very Thin PCBM and LiF Layers for Solution-Processed p-i-n Perovskite Solar Cells. Energy and Environmental Science, 7, 2642-2646. https://doi.org/10.1039/C4EE01216J

[15] Liu, Z., Zhu, A., Cai, F., Tao, L., Zhou, Y., Zhao, Z., Chen, Q., Cheng, Y.-B. and Zhou, H.P. (2017) Nickel Oxide Nanoparticles for Efficient Hole Transport in p-i-n and n-i-p Perovskite Solar Cells. Journal of Materials Chemistry, 5, 6597-6605. https://doi.org/10.1039/C7TA01593C

[16] Kim, H.-S. and Park, N.-G. (2014) Parameters Affecting $I-V$ Hysteresis of $\mathrm{CH}_{3} \mathrm{NH}_{3} \mathrm{PbI}_{3}$ Perovskite Solar Cells: Effects of Perovskite Crystal Size and Mesoporous $\mathrm{TiO}_{2}$ Layer. Journal of Physical Chemistry Letter, 5, 2927-2934. https://doi.org/10.1021/jz501392m

[17] Liu, D., Li, S., Zhang, P., Wang, Y., Zhang, R., Sarvari, H., Wang, F., Wu, J., Wang, Z. and Chen, Z.D. (2017) Efficient Planar Heterojunction Perovskite Solar Cells with Li-Doped Compact $\mathrm{TiO}_{2}$ Layer. Nano Energy, 31, 462-468. https://doi.org/10.1016/j.nanoen.2016.11.028

[18] Liu, D., Li, Y., Yuan, J., Hong, Q., Shi, G., Yuan, D., Wei, J., Huang, C., Tang, J. and Fung, M.-K. (2017) Improved Performance of Inverted Planar Perovskite Solar Cells with F4-TCNQ Doped PEDOT: PSS Hole Transport Layers. Journal of Materials Chemistry, 5, 5701-5708. https://doi.org/10.1039/C6TA10212C

[19] Zhao, Q., Wu, R., Zhang, Z., Xiong, J., He, Z., Fan, B., Dai, Z., Yang, B., Xue, X., et 
al. (2019) Achieving Efficient Inverted Planar Perovskite Solar Cells with Nondoped PTAA as a Hole Transport Layer. Organic Electronics, 71, 106-112. https://doi.org/10.1016/j.orgel.2019.05.019

[20] Yang, S., Dai, J., Yu, Z., Shao, Y., Zhou, Y., Xiao, X., Zeng, X.C. and Huang, J.J. (2019) Tailoring Passivation Molecular Structures for Extremely Small Open-Circuit Voltage Loss in Perovskite Solar Cells. Journal of the American Chemical Society, 141, 5781-5787. https://doi.org/10.1021/jacs.8b13091

[21] Xu, L., Chen, X., Jin, J., Liu, W., Dong, B., Bai, X., Song, H. and Reiss, P. (2019) Inverted Perovskite Solar Cells Employing Doped NiO Hole Transport Layers: A Review. Nano Energy, 63, Article ID: 103860. https://doi.org/10.1016/j.nanoen.2019.103860

[22] Li, M., Xu, X., Xie, Y., Li, H.-W., Ma, Y., Cheng, Y. and Tsang, S.-W. (2019) Improving the Conductivity of Sol-Gel Derived $\mathrm{NiO}_{x}$ with a Mixed Oxide Composite to Realize over $80 \%$ Fill Factor in Inverted Planar Perovskite Solar Cells. Journal of Materials Chemistry, 7, 9578-9586. https://doi.org/10.1039/C8TA10821H

[23] Arora, N., Dar, M.I., Hinderhofer, A., Pellet, N., Schreiber, F., Zakeeruddin, S.M. and Grätzel, M. (2017) Perovskite Solar Cells with CuSCN Hole Extraction Layers Yield Stabilized Efficiencies Greater than 20\%. Science, 358, 768-771. https://doi.org/10.1126/science.aam5655

[24] Yu, Z. and Sun, L.C. (2018) Inorganic Hole-Transporting Materials for Perovskite Solar Cells. Small Methods, 2, Article ID: 1700280. https://doi.org/10.1002/smtd.201700280

[25] Sun, W., Ye, S., Rao, H., Li, Y., Liu, Z., Xiao, L., Chen, Z., Bian, Z. and Huang, C. (2016) Room-Temperature and Solution-Processed Copper Iodide as the Hole Transport Layer for Inverted Planar Perovskite Solar Cells. Nanoscale, 8, 15954-15960. https://doi.org/10.1039/C6NR04288K

[26] Bryant, D., Wheeler, S., O’Regan, B.C., Watson, T., Barnes, P.R., Worsley, D. and Durrant, J. (2015) Observable Hysteresis at Low Temperature in "Hysteresis Free" Organic-Inorganic Lead Halide Perovskite Solar Cells. Journal of Physical Chemistry Letters, 6, 3190-3194. https://doi.org/10.1021/acs.jpclett.5b01381

[27] Xu, J., Buin, A., Ip, A.H., Li, W., Voznyy, O., Comin, R., Yuan, M., Jeon, S., Ning, Z., et al. (2015) Perovskite-Fullerene Hybrid Materials Suppress Hysteresis in Planar Diodes. Nature Communications, 6, Article No. 7081. https://doi.org/10.1038/ncomms8081

[28] Shao, Y., Xiao, Z., Bi, C., Yuan, Y. and Huang, J. (2014) Origin and Elimination of Photocurrent Hysteresis by Fullerene Passivation in $\mathrm{CH}_{3} \mathrm{NH}_{3} \mathrm{PbI}_{3}$ Planar Heterojunction Solar Cells. Nature Communications, 5, Article No. 5784. https://doi.org/10.1038/ncomms6784

[29] Chiang, C.-H. and Wu, C.-G. (2016) Bulk Heterojunction Perovskite-PCBM Solar Cells with High Fill Factor. Nature Photonics, 10, 196-200. https://doi.org/10.1038/nphoton.2016.3

[30] Shockley, W. and Queisser, H.J. (1961) Detailed Balance Limit of Efficiency of p-n Junction Solar Cells. Journal of Applied Physics, 32, 510-519. https://doi.org/10.1063/1.1736034

[31] Chen, C., Song, Z., Xiao, C., Zhao, D., Shrestha, N., Li, C., Yang, G., Yao, F., Zheng, X., et al. (2019) Achieving a High Open-Circuit Voltage in Inverted Wide-Bandgap Perovskite Solar Cells with a Graded Perovskite Homojunction. Nano Energy, 61, 141-147. https://doi.org/10.1016/j.nanoen.2019.04.069

[32] Choi, K., Lee, J., Kim, H.I., Park, C.W., Kim, G.-W., Choi, H., Park, S., Park, S.A. 
and Park, T.J.E. (2018) Thermally Stable, Planar Hybrid Perovskite Solar Cells with High Efficiency. Energy and Environmental Science, 11, 3238-3247. https://doi.org/10.1039/C8EE02242A

[33] Yang, B., Dyck, O., Poplawsky, J., Keum, J., Puretzky, A., Das, S., Ivanov, I., Rouleau, C., Duscher, G., Geohegan, D. and Xiao, K. (2015) Perovskite Solar Cells with near $100 \%$ Internal Quantum Efficiency Based on Large Single Crystalline Grains and Vertical Bulk Heterojunctions. Journal of the American Chemical Society, 137, 9210-9213. https://doi.org/10.1021/jacs.5b03144

[34] Wu, W.-Q., Wang, Q., Fang, Y., Shao, Y., Tang, S., Deng, Y., Lu, H., Liu, Y., Li, T., Yang, Z., Gruverman, A. and Huang, J. (2018) Molecular Doping Enabled Scalable Blading of Efficient Hole-Transport-Layer-Free Perovskite Solar Cells. Nature Communications, 9, Article No. 1625. https://doi.org/10.1038/s41467-018-04028-8

[35] Hou, F., Su, Z., Jin, F., Yan, X., Wang, L., Zhao, H., Zhu, J., Chu, B. and Li, W. (2015) Efficient and Stable Planar Heterojunction Perovskite Solar Cells with an $\mathrm{MoO}_{3} /$ PEDOT: PSS Hole Transporting Layer. Nanoscale, 7, 9427-9432. https://doi.org/10.1039/C5NR01864A

[36] Zuo, C. and Ding, L. (2017) Modified PEDOT Layer Makes a $1.52 \mathrm{~V} V_{o c}$ for Perovskite/PCBM Solar Cells. Advanced Energy Materials, 7, Article ID: 1601193. https://doi.org/10.1002/aenm.201601193

[37] Yan, W., Li, Y., Li, Y., Ye, S., Liu, Z., Wang, S., Bian, Z. and Huang, C. (2015) High-Performance Hybrid Perovskite Solar Cells with Open Circuit Voltage Dependence on Hole-Transporting Materials. Nano Energy, 16, 428-437. https://doi.org/10.1016/j.nanoen.2015.07.024

[38] Sun, S., Salim, T., Mathews, N., Duchamp, M., Boothroyd, C., Xing, G., Sum, T.C. and Lam, Y.M. (2014) The Origin of High Efficiency in Low-Temperature Solution-Processable Bilayer Organometal Halide Hybrid Solar Cells. Energy and Environmental Science, 7, 399-407. https://doi.org/10.1039/C3EE43161D

[39] D’innocenzo, V., Grancini, G., Alcocer, M.J., Kandada, A.R.S., Stranks, S.D., Lee, M.M., Lanzani, G., Snaith, H.J. and Petrozza, A. (2014) Excitons versus Free Charges in Organo-Lead Tri-Halide Perovskites. Nature Communications, 5, Article No. 3586. https://doi.org/10.1038/ncomms4586

[40] Liu, M., Chen, Z., Yang, Y., Yip, H.-L. and Cao, Y. (2019) Reduced Open-Circuit Voltage Loss for Highly Efficient Low-Bandgap Perovskite Solar Cells via Suppression of Silver Diffusion. Journal of Materials Chemistry A, 7, 17324-17333. https://doi.org/10.1039/C9TA04366G

[41] Yuan, J., Huang, T., Cheng, P., Zou, Y., Zhang, H., Yang, J.L., Chang, S.-Y., Zhang, Z., Huang, W., et al. (2019) Enabling Low Voltage Losses and High Photocurrent in Fullerene-Free Organic Photovoltaics. Nature Communications, 10, Article No. 570. https://doi.org/10.1038/s41467-019-08386-9

[42] Li, W., Hendriks, K.H., Furlan, A., Wienk, M.M. and Janssen, R.A.J. (2015) High Quantum Efficiencies in Polymer Solar Cells at Energy Losses below $0.6 \mathrm{eV}$. Journal of the American Chemical Society, 137, 2231-2234. https://doi.org/10.1021/ja5131897

[43] Zhao, Y., Li, Q., Zhou, W., Hou, Y., Zhao, Y., Fu, R., Yu, D., Liu, X. and Zhao, Q. (2019) Double-Side-Passivated Perovskite Solar Cells with Ultra-Low Potential Loss. Solar RRL, 3, Article ID: 1800296. https://doi.org/10.1002/solr.201800296 


\section{Support Information}

Table S1. Detailed photovoltaic parameters of the PSCs based on ITO/PEDOT:PSS with different PCBM contents.

\begin{tabular}{ccccc}
\hline Dope ratio of PCBM $(\mathrm{wt} \%)$ & $V_{o c}(\mathrm{~V})$ & $J_{s c}\left(\mathrm{~mA} / \mathrm{cm}^{2}\right)$ & Fill factor $(\%)$ & PCE (\%) \\
\hline 0.00 & 0.82 & 15.63 & 70.29 & 9.01 \\
0.25 & 0.82 & 15.63 & 71.60 & 9.22 \\
0.50 & 0.84 & 16.56 & 70.69 & 9.77 \\
0.75 & 0.93 & 17.11 & 64.14 & 10.19 \\
1.00 & 0.99 & 18.06 & 66.50 & 11.89 \\
1.25 & 0.89 & 17.15 & 64.85 & 9.94 \\
1.50 & 0.84 & 17.75 & 63.06 & 9.42 \\
\hline
\end{tabular}

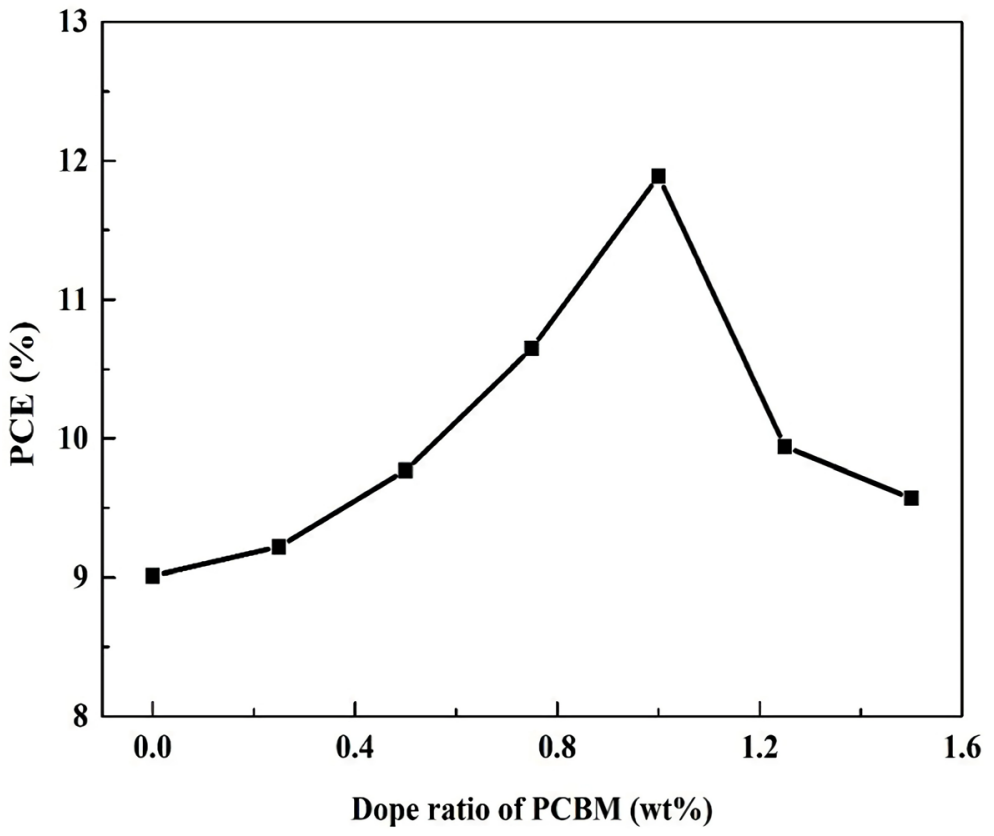

Figure S1. The PCE of pristine and PCBM as additive in the absorber layer perovskite solar cells. 